\title{
Lo real maravilloso y la visión estético-cultural de América Latina
}

\section{THE REAL MARAVILLOSO AND THE AESTHETIC-CULTURAL VISION OF LATIN AMERICA}

Reynaldo Santa Cruz

Universidad de Lima

\section{RESUMEN}

Este artículo se concentra en registrar las diversas características que distinguen a la producción estética latinoamericana, expresada en el código de lo real maravilloso. A través de esta descripción se puede detectar la esencia cultural de nuestro continente y las variables que convierten a nuestra herencia artística en un fenómeno muy particular, que obedece a factores sociohistóricos y que, por lo mismo, son parte de nuestro capital simbólico. En este recorrido panorámico, en el cual desfilan elementos del tema en cuestión, como contexto, sincretismo y autores, se pueden identificar algunos rasgos representativos y recurrentes en el desarrollo artístico latinoamericano, los que corresponden, como ya se señaló, a ciertas marcas que nos distinguen. Estos factores estructurales proceden de nuestra propia idiosincrasia y, por eso, resultan difíciles de percibir, puesto que hemos naturalizado sus manifestaciones $y$, con ello, hemos creado una barrera imperceptible para su posible análisis.

El eje temático, sin duda, fue el gran capital simbólico de nuestro continente y la riqueza que entraña la diversidad. Finalmente, el texto pretende reparar en la originalidad y creatividad de un estilo que trasciende lo literario, como es lo real maravilloso.

PALABRAS CLAVE: arte, literatura, real maravilloso,

\section{ABSTRACT}

The article is presented in registering the various characteristics that distinguish Latin American aesthetic production, expressed in the code of the real maravilloso. Throug this description it is posible to detect the cultural essence of our continent and the variables that make our artistic heritage a very particular phenomenon, the same that is due to sociohistorical factors, and that, therefore are part of our symbolic capital. Throug a panoramic tour in which elements of the subject in question parade, such as context syncretism and authors; it was posible to identify some representative and recurrent features in Latin American artistic development, which correspond, as already indicated, to certain brands that distinguish us. These structural factors come from our own idyosincrasy and, therefore, are difficult to perceive, since we have naturalized their manifestations and with this, we have created and imperceptible barrier for their posible analysis. The thematic axis, without a doubt, was the great symbolic capital of our continent and the richness that diversity entails. Finally, the text aims to repair the originality and creativity of a style that transcends athe literary such as the real maravilloso.

KEYWORDS: art, literature, real maravilloso, misgeneration, Latin America mestizaje, Latinoamérica 
El término lo real maravilloso americano es el resultado de un proceso poco común; no ha sido aclarado mediante definición o manifiesto; por el contrario, ha sido descrito por su creador como una intuición. Carpentier nunca pudo dar una definición y, cuando lo intentó, lo hizo sin comprometerse del todo, ya que la definición cambiaba permanentemente para adaptarse a los distintos fenómenos en Latinoamérica. En algún momento, incluso, llegó a afirmar que lo real maravilloso latinoamericano también podía ser entendido como lo real-horroroso.

Por lo tanto, al formular la pregunta por el significado del término lo real maravilloso americano es necesario hacer un recuento de su historia y de cómo Carpentier vio su desarrollo en Latinoamérica. (Bernal, 2006, p. 33)

Alejo Carpentier, en su célebre prólogo de El reino de este mundo (1949/1994), se distancia del espíritu anquilosado que anima a los surrealistas o, en todo caso, a los autores que jugaron con la combinación de elementos realistas y fantásticos. Observa desencantado la reiteración sistemática de recursos y estrategias que, por lo mismo, aparece incolora e inexpresiva. Su crítica es irónica y feroz. Acusa con radicalismo, pero sobre todo con inmensa razón. No, esa desgastada tautología estética no podía ser lo que él buscaba representar como artista y esencialmente como latinoamericano.

\begin{abstract}
A fuerza de querer suscitar lo maravilloso a todo trance, los taumaturgos se hacen burócratas. Invocado por medio de fórmulas consabidas que hacen de ciertas pinturas un monótono baratillo de relojes amelcochados, de maniquíes de costurera, de vagos monumentos fálicos, lo maravilloso se queda en paraguas o langosta o máquina de coser, o lo que sea, sobre una mesa de disección, en el interior de un cuarto triste, en un desierto de rocas. Pobreza imaginativa, decía Unamuno, es aprender códigos de memoria. (Carpentier, 1949/1994, p. 6)
\end{abstract}

Citar en esta diatriba a Unamuno es apelar a uno de los más notables escritores y filósofos europeos, pero es también contraponer a un autor que se caracterizó por su originalidad y por sus propuestas innovadoras. Pocos como Unamuno pueden ejercer el derecho de cuestionar la ausencia de creatividad y su síntoma más representativo: la repetición.

Pero es que muchos se olvidan, con disfrazarse de magos a poco costo, que lo maravilloso comienza a serlo de manera inequívoca cuando surge de una inesperada alteración de la realidad (el milagro), de una revelación privilegiada de la realidad, de una iluminación inhabitual, singularmente favorecedoras de las inadvertidas riquezas de la realidad, de una ampliación de las escalas y categorías de la realidad, percibidas con particular intensidad en virtud de una exaltación del espíritu que lo conduce a un modo de "estado límite". (Carpentier, 1949/1994, p. 7)

El ángulo desde el que Carpentier enfoca el fenómeno de lo real maravilloso procede, entonces, de su crítica al esteticismo, a la falta de sorpresa que convierte a la realidad en 
algo rutinario. La realidad, desde su perspectiva, es muchísimo más asombrosa y rica en niveles y connotaciones como para reproducirla fielmente o, en el peor de los casos, para tratar de extraerla de su cotidianidad por medio de recursos repetidos y previsibles.

El milagro, categoría muy importante, desencadena con su poder explosivo la sensación de estado límite que permite al hombre latinoamericano experimentar lo sobrenatural. Sin embargo, la idea fuerza de lo real maravilloso es la concepción carpenteriana de fe:

Para empezar, la sensación de lo maravilloso presupone una fe. Los que no creen en santos no pueden curarse con milagros de santos, ni los que no son quijotes pueden meterse, en cuerpo, alma y bienes, en el mundo de Amadís de Gaula o Tirante el Blanco. Prodigiosamente fidedignas resultan ciertas frases de Rutilio en Los trabajos de Persiles y Sigismunda acerca de hombres transformados en lobos, porque en tiempos de Cervantes se creía en gentes aquejadas de manía lupina. (Carpentier, 1949/1994, p. 8)

El presupuesto de una fe para creer en todo lo que la realidad puede ofrecer es esencial en la conformación de lo real maravilloso. Así hubiera desmesura, así hubiera novedad y creatividad, así se efectuara el "milagro", de nada serviría si el hombre careciera de fe, si no estuviera dotado de esa cualidad espiritual - y también cultural- que obra en él como el catalizador de esa característica innata en nuestro imaginario. Por tanto, la ausencia de fe, o la mecanización cultural que terminó por asfixiarla, condenó a los surrealistas europeos:

De ahí que lo maravilloso invocado en el descreimiento - como lo hicieron los surrealistas durante tantos años- nunca fue sino una artimaña literaria, tan aburrida al prolongarse, como cierta literatura onírica "arreglada", ciertos elogios de la locura, de los que estamos muy de vuelta. No por ello va a darse la razón, desde luego, a determinados partidarios de un regreso a lo real -término que cobra, entonces, un significado gregariamente político-, que no hacen sino sustituir los trucos del prestidigitador por los lugares comunes del literato "enrolado" o el escatológico regodeo de ciertos existencialistas. (Carpentier, 1949/1994, p. 8)

La interlínea del texto nos advierte que, más allá de la falta de fe, el otro gran inconveniente para alcanzar el efecto del asombro, de la sorpresa en la obra estética, es la artificialidad. A la ya aludida reiteración del recurso "novedoso" o de ruptura, el autor realiza una maniobra literaria en la que no cree, solo repite trucos y artimañas buscando sacudir al lector. Sin embargo, este realismo fantástico militante y mecánico no logra su propósito desestabilizador; su mirada negadora de la realidad se convierte en una mueca más, estudiada y concesiva, una efímera moda estética.

En cualquier caso, lo que parece fuera de discusión es que lo real maravilloso americano y el realismo mágico son una consecuencia de los planteamientos aportados por la vanguardia en los años veinte, y de la idea de América que 
desarrollaron. La pretensión de ver el mundo con ojos nuevos exigió que se viese como si acabase de surgir de la nada. (Fernández, 2001, p. 289)

Lo que se puede reconocer claramente, y ni siquiera el propio Carpentier intentó negar, es la deuda que siempre tuvo con el movimiento liderado por Breton. La influencia que trascendió los personalismos de las cabezas del credo surrealista ejerció sobre la obra del cubano un poderoso estímulo, que estuvo conformado por lo emotivo, lo cultural y también por una mirada nueva de lo mismo. La oposición entre la vieja Europa, racional, equilibrada, pero achacosa y desgastada, con la América auroral, salvaje y espontánea significó un encuentro que para Carpentier debía ir más allá del mutuo conocimiento.

Nada más adecuado al respecto que una América joven o niña observada por un Occidente que se decía en decadencia y se mostraba ávido de maravilla, como prueba un arte que entonces extendía sus dominios al ámbito de lo irracional, a los misterios del sueño y del subconsciente. En esa tendencia se inscribe el surrealismo, que, como es bien sabido, descubrió a Carpentier los derechos de la magia y la necesidad de la fe en realidades superiores. Aplicadas a América esa necesidad y esa fe, la convirtieron en el continente del origen o del tiempo sin tiempo, en la concreción de la utopía que el intelectualizado y artificial surrealismo europeo no había conseguido alcanzar, en el lugar donde las distancias entre la historia y el mito desaparecen. Esas aspiraciones encontraban un terreno abonado: al menos desde los años veinte se había extendido la convicción de que el mito constituía la manera de pensar de los primitivos, carentes de memoria histórica. (Fernández, 2001, p. 290)

Es natural que Carpentier solo percibiera la primera fase de esta concepción, es decir, aquella en la que la agotada Europa, ahogada en artificios, cuyo arquetipo sería el surrealismo, precisa de una renovación que no podía hallar en su propio espacio cultural. Pero es en la segunda concepción, la de una Latinoamérica estática, colorida, espontánea y anárquica, en la que yace otra lectura de lo real maravilloso. Esta última no pudo ser atendida por el narrador cubano y no porque él no lo deseara, sino porque carecía de la distancia en el tiempo para verla en perspectiva.

Es muy sencillo desbaratar el andamiaje teórico de Carpentier seis décadas luego de su construcción, pero ese no es un ejercicio de actualización de su discurso; por el contrario, aparece como un ingenuo anacronismo. La evaluación negativa de los diversos movimientos artísticos europeos tiene que ver con la comparación que el escritor hizo con las manifestaciones auténticas de lo real maravilloso.

Esto se me hizo particularmente evidente durante mi permanencia en Haití, al hallarme en contacto cotidiano con algo que podríamos llamar lo real maravilloso. Pisaba yo una tierra donde millares de hombres ansiosos de libertad creyeron en los poderes licantrópicos de Mackandal, a punto de que esa fe colectiva produjera un milagro el día de su ejecución [...] había respirado la atmósfera creada por Henri Christophe, monarca de increíbles empeños, mucho más sorprendentes que todos 
los reyes crueles inventados por los surrealistas, muy afectos a tiranías imaginarias, aunque no padecidas. (Carpentier, 1949/1994, p. 9)

Aunque Carpentier continúa fustigando a los surrealistas, a quienes considera poco auténticos, lo importante de la cita es su descubrimiento de esa dimensión mítica que es lo real maravilloso. Haití, un país que combina la vieja herencia europea con el imaginario africano, se convirtió en su primera escuela. Ahí encontró la fe, a la que consideraba esencial para captar las señales de esa otra realidad.

Al final del párrafo, ironiza con respecto a la visión eurocéntrica y cómoda de los surrealistas; critica su distanciamiento de los hechos que posteriormente van a retratar.

A cada paso hallaba lo real maravilloso. Pero pensaba, además, que esa presencia y vigencia de lo real maravilloso no era privilegio único de Haití, sino patrimonio de la América entera, donde todavía no se ha terminado de establecer, por ejemplo, un recuento de cosmogonías. Lo real maravilloso se encuentra a cada paso en las vidas de los hombres que inscribieron fechas en la historia del continente [...] siempre me ha parecido significativo el hecho de que, en 1780, unos cuerdos españoles, salidos de Angostura, se lanzaran todavía a la busca de El Dorado, y que, en días de la Revolución francesa - ¡vivan la Razón y el Ser Supremo!-, el compostelano Francisco Menéndez anduviera por tierras de Patagonia buscando la Ciudad de los Césares [...] ¿Pero qué es la historia de América toda sino una crónica de lo real maravilloso? (Carpentier, 1949/1994, p. 11)

Lo que en un principio significó el asombro ante cierto episodio histórico-mítico acaecido en Haití se convirtió luego en una reflexión que hizo a Carpentier remontarse y bucear en la historia de Latinoamérica. De este modo, el escritor cubano, en un brevísimo recuento cronológico, ubica sucesos y personajes que se acomodan perfectamente a las nociones que sostienen el edificio de lo real maravilloso. Qué, si no fe, impulsó a un grupo de españoles de la era racionalista a buscar El Dorado. Qué, si no fe, empujó a Menéndez hasta la Patagonia para hallar la Ciudad Encantada de los Césares... Carpentier culmina el comentario con una interrogante, que se ha convertido prácticamente en el manifiesto de lo real maravilloso.

Uno de los estudios más concienzudos de esta variante narrativa fue realizado por el crítico y novelista peruano José Antonio Bravo. Este académico contribuye a sistematizar la propuesta carpenteriana e incluso califica sus componentes.

Hasta aquí tenemos seis elementos importantes para el análisis:

Primero: la fe.

Segundo: personas que tienen fe.

Tercero: personas que tienen fe en alguien.

Cuarto: este alguien posee atributos superiores. 
Quinto: estos atributos superiores que tiene alguien se ponen de manifiesto delante de la gente que cree.

Sexto: esta revelación, este hecho extraordinario, se llama milagro.

Séptimo: tanto el autor como sus personajes tienen fe en acontecimientos extraordinarios.

Octavo: el lugar geográfico donde se dan estos acontecimientos es América. (Bravo, 1978, p. 28)

Esta división por etapas, a la manera de una jerarquización o un esquema de grados y matices, es muy útil, puesto que agrupa los diferentes componentes que conforman lo real maravilloso. De la unión y mezcla de todos ellos surgirá aquella atmósfera tan característica de nuestros pueblos, trasladada luego a la obra literaria. Cada una de las etapas señaladas por Bravo (1978) funciona como un cerco que va encerrando al lector en este universo único.

Para Carpentier, la naturaleza en Latinoamérica es algo prodigioso que adquiere dimensiones que superan cualquier aprehensión, estimulando un sentimiento de maravilla y asombro. Según él, esto se debe al hecho de que, a diferencia de la naturaleza europea, la naturaleza latinoamericana no ha sido dominada; es silvestre y salvaje. (Bernal, 2006, p. 37)

La producción teórica y estética de Carpentier, naturalmente, fue estructurada de manera coherente y luego de la confrontación con los modelos surrealistas. Además, la difusión de su obra fue amplia y exitosa.

Con respecto al gran narrador cubano, José María Arguedas se muestra distante y hasta irónico. Cuando se ocupa de la inteligencia del autor de El reino de este mundo dice: "Penetra las cosas de afuera adentro como un rayo; es un cerebro que recibe, lúcido y regocijado, la materia de las cosas" (Arguedas, 2004, p. 179). Ese privilegiar la racionalidad implica, por oposición lógica, que Arguedas sentía que Carpentier entendía al mundo y a sus manifestaciones como razones o hechos percibidos racionalmente; en cambio, él sentía que poseía un vínculo más emotivo, más sensorial con la realidad que se le presentaba. Estas diferencias que Arguedas remarca directa o indirectamente no obstruyen su incursión en el mismo espacio estilístico: el de lo real maravilloso.

Arguedas se acerca a la realidad por otros caminos, más intuitivos y más trágicos, lo que prueba que lo real maravilloso no fue una moda, sino una posibilidad válida de interpretar lo nuestro, adoptada incluso por quien, como Arguedas, se ubicaba emocionalmente distante de él. (Rodríguez, 2004, p. 66)

Ante esta posible diferencia de concepto entre Arguedas y Carpentier, debemos considerar la divergencia de percepción como una saludable expresión de los matices 
que puede mostrar esta tendencia y, a partir de ella, conseguir una mejor comprensión sobre nuestra naturaleza, concebida como una multiplicidad de rasgos y actitudes heterogéneos que construyen directa e indirectamente aquello que llamamos identidad.

Esta tendencia de origen latinoamericano revela, como muy pocas, la encrucijada en la que se encuentran nuestros pueblos, es decir, la de volcarse a la caza de una serie de rasgos plurales y sincréticos que nos permitan hablar de una identidad, que más allá de las proclamas retóricas, es una necesidad urgente para reconocernos y comprendernos. Lo real maravilloso, excelente punto medio entre la perspectiva social y la literaria, es, pues, desde el lado estético, toda una representación de esa ansiedad por conocernos y de llegar — desde esa visión introspectiva— al núcleo de nuestra condición.

Desde luego que ambos componentes de este enfoque latinoamericano crean sus propios límites y a la vez sus particulares vacíos. Por ejemplo, lo antropológico esgrimirá su rigor en la metodología y su relación mimética con la realidad concreta, razones implícitas de esta disciplina; y lo literario dejará en claro que las relaciones entre la realidad "real" y la "ficticia" son arbitrarias y no tienen la obligación de establecer paralelismos rígidos. Pero, en líneas generales, esas señales fronterizas e irreductibles, en cualquier caso que tratemos de forzar una perspectiva uniforme, se vuelven, paradójicamente, difusas y hasta invisibles en el tema específico de lo real maravilloso, puesto que, si existe un limbo donde las categorías conceptuales se ven oscilantes, ese es precisamente el ámbito en el que se expresa el movimiento estético que es materia de nuestro análisis.

Desde luego, cada cual puede tener la opinión que considere más oportuna sobre la realidad y sobre sus relaciones con la literatura. Lo que nadie puede no advertir, y eso resulta decisivo, es que la referencia de lo natural, de lo razonable o verosímil continúa posibilitando la percepción de las diferencias. Antes era la pobre lógica de cada día la que permitía apreciar la aparición de lo inexplicable. Ahora, y claramente en el caso de Carpentier, es la implacable lógica del racionalismo, que se considera ajena, lo que permite valorar la excepcionalidad del mundo americano. (Fernández, 2001, pp. 292-293)

El esquema de los opuestos complementarios se expresa en toda su amplitud al invertirse las categorías que usualmente se habían constituido como las hegemónicas en el proceso evolutivo que ha seguido la cultura occidental. De esta manera, las dos magnitudes que se le asignan a la lógica crean la dinámica que permite el despliegue de lo real maravilloso. El aparentemente sólido constructo racionalista mostró sus fisuras y a través de ellas se ha podido manifestar esa excepcionalidad americana a la que Fernández (2001) hace referencia. Por ello, lo real maravilloso ofrece una oportunidad poco común de fusión o compenetración interdisciplinaria y, al mismo tiempo, significa una preocupación continental por nuestra naturaleza y conformación étnica, artística, social y psicológica. 
Entonces, si armonizamos el interés que el tema reviste por el lado formal y por el temático, estamos ante la mayor justificación que este puede poseer en sí mismo y, por lo tanto, su esfericidad como motivo nos exime de criterios ajenos a su naturaleza y de interpretaciones metatextuales, ciñéndonos a los puntos en los que la literatura y el contexto sociocultural van de la mano.

Entretanto, en el viejo continente europeo, el mundo cultural ya estaba listo para la aparición de Latinoamérica en el mapa. La vanguardia, especialmente el surrealismo, había luchado por la aceptación del Otro como un factor cultural valioso. El camino había sido preparado por el desencanto general hacia la civilización europea después de la Primera Guerra Mundial, resumido por Oswald Spengler en su libro La decadencia de Occidente (1918). No obstante, aparecer en el mapa cultural no era suficiente; la "aceptación" que manifestaba Europa distaba mucho de ser aquella buscada por Latinoamérica. Se trataba de una aceptación que mantenía la diferencia entre Europa, como centro civilizado, y el subcontinente, como el Otro. En otras palabras, era una concepción de Latinoamérica que dependía de y cuya identidad se enmarcaba en términos de los preconceptos ideológicos del discurso hegemónico de Occidente. De allí que el Otro fuera reconocido solamente como fuente de entretenimiento exótico y experiencias revitalizadoras, quitándole de esa manera cualquier legitimidad a la cultura latinoamericana. (Bernal, 2006, p. 13)

Más allá de lo que a estructura se refiere, el tema de lo real maravilloso, y sobre todo sus consecuencias, nos obliga a establecer criterios reflexivos acerca de nuestra identidad. Por ello, aunque no pretendamos dualidades básicas como fondo y forma, se puede hallar en él una complementación natural: "Un rasgo distintivo de lo real maravilloso es que su método maneja un lenguaje artístico por excelencia en el plano de la expresión y valores documentales en el plano del contenido" (Asenov, 1986, p. 19).

Esta división puede parecer artificial; sin embargo, es una manera de identificar a lo real maravilloso como un movimiento ambiguo y dual, fácilmente desmontable en sus partes constitutivas. Notamos, por ejemplo, de qué manera funciona su dinámica interna al bifurcarse en dos niveles racionales, como los que corresponden a la teoría y al método; esto ubica al escritor no solo como un artista forjador de discursos puramente estéticos, sino incluso como un creador en el cumplimiento de su función intelectual:

Lo real maravilloso es un fenómeno literario oriundo de Latinoamérica, es a la vez una teoría y un método. Lo real maravilloso implica una ardua labor en dos direcciones: por una parte, requiere un estudio exhaustivo del mayor número de facetas de la realidad y, por otra, un enfoque valorativo de la misma que niega determinados sistemas axiológicos y confirma otros. Esto significa que el escritor es más que un simple registrador de hechos y fenómenos y que la obra no es solo un signo estético, sino que cumple una función ancilar que la incorpora a una de las tradiciones más entrañables de la literatura hispanoamericana. (Asenov, 1986, p. 20) 
Sin embargo, esta cita no aclararía el panorama si no tomamos en cuenta que lo real maravilloso como visión del mundo se propone forjar, sobre la base de la realidad, una imagen verosímil de ese universo concreto que es su referente. Este reflejo estético está organizado sobre fundamentos firmes e instrumentos metodológicos que incluyen la unicidad u originalidad de los hechos y fenómenos de la realidad, el sincretismo que implica el mestizaje y el contraste de dichos elementos para perfilarlos. Normalmente, estas tres características caminan juntas y producen, finalmente, el asombro, la sorpresa y el impacto definitivo en los lectores. De este modo, el método de lo real maravilloso obliga al lector a rastrear $y$, después, a asumir una toma de conciencia acerca de la identidad latinoamericana.

En consecuencia, el realismo mágico constituyó la respuesta literaria a una determinada concepción de América, y en ese contexto ha de analizarse su posible relación con la literatura fantástica. Esa concepción de América respondía a la convicción declarada de que existían formas de pensamiento distintas a la gobernada por la lógica o el racionalismo, antes la única legítima y ahora identificada con la represión de los instintos y con el imperialismo europeo o norteamericano. Frente a esta, $y$ frente a lo que se supone su pobreza imaginativa, esas otras formas de pensamiento tienen que ver con lo mágico, con lo prodigioso, con lo sobrenatural, que se insertan sin dificultades en un orden distinto, en una "realidad" (en una visión del mundo) que no siente necesidad alguna de ser razonable. En esa otra lógica bien puede el tiempo retroceder respondiendo a un conjuro, y un hombre transformarse en animal, y una doncella subir al cielo envuelta en una sábana.

En el mundo americano lo extraordinario deja de serlo, de modo que la literatura del realismo mágico sería un testimonio fiel (realista) de lo real maravilloso de América. (Fernández, 2001, p. 292)

Es sintomático que Fernández proponga el término respuesta, ya que este implica un papel activo de nuestra cultura, un reconocerse y asumirse como interlocutor válido en el diálogo que usualmente tenía carácter asimétrico y que encarnaba en lo colectivo la noción del sujeto subalterno.

De este modo, Europa no solamente interactuaba con América Latina, sino que permanecía silenciosa, desbordada por el caudal creativo de esta parte del continente. La Europa que había producido en el xix la más notable explosión y auge de la novela, y que prácticamente había agotado el género, se halló en una encrucijada: los recursos narrativos innovadores que utilizaron no pudieron ocultar la falta de imaginación, la rutina creativa del realismo, que entraba en franca decadencia a inicios del siglo xx. Era inevitable, por lo mismo, que el decrépito discurso racionalista y la lógica esquemática occidental dieran paso a un modelo innovador y natural, que no precisó de un manifiesto o de una revolución estética; por el contrario, siempre estuvo allí, ajeno al proceso dialéctico al que fue sometido el arte en Europa. 
La actitud de parte de los receptores, para aceptar la ficción, es posible gracias a un deslinde que existe entre lo real maravilloso falso y el verdadero. Dentro del primero estaría la visión deliberadamente deformada que tuvieron los españoles al llegar a América, deformación creada por razones religiosas, encubridoras y oportunistas, o, en todo caso, confundidas con el imaginario popular medieval, que concebía a Latinoamérica como un espacio vacío donde se podrían incluir los bestiarios europeos y toda la gama de seres mágicos y temores colectivos.

El "realismo maravilloso" plantea la coexistencia no problemática de lo real y lo sobrenatural en un mundo semejante al nuestro [...]. Una situación que se consigue mediante un proceso de naturalización (verosimilización) y de persuasión, que confiere estatus de verdad a lo no existente. El realismo maravilloso descansa sobre una estrategia fundamental: desnaturalizar lo real y naturalizar lo insólito, es decir, integrar lo ordinario y lo extraordinario en una única representación del mundo. Así los hechos son presentados al lector como si fueran algo corriente. $Y$ el lector, contagiado por el tono familiar del narrador y la falta de asombro de este y de los personajes, acaba aceptando lo narrado como algo natural. (Roas, 2001, p. 12)

El efecto de la naturalización es esencial para percibir a lo real maravilloso como una manifestación espontánea 0 , al menos, para que ella lo parezca en el conjunto de obras que suelen agruparse en torno a este movimiento. El receptor desbordado por el efecto ambiguo que genera lo real maravilloso es sometido a los designios del creador, que interpreta y muestra esta compleja realidad sin ninguna inflexión, con la misma naturalidad con la que se expresaría en cualquier acto rutinario de su vida.

No se trata, por lo tanto, de crear un mundo radicalmente distinto al del lector, como es el de lo maravilloso, sino que en estas narraciones lo irreal aparece como parte de la realidad cotidiana, lo que significa, en definitiva, superar la oposición natural/sobrenatural sobre la que se construye el efecto fantástico. Podríamos decir, en conclusión, que se trata de una forma híbrida entre lo fantástico y lo maravilloso. (Roas, 2001, p. 13)

La oposición de la que se nos habla entre natural y sobrenatural pertenece al concepto común de la realidad, es decir, a esa convención que Occidente ha aceptado desde tiempos antiguos y que tuvo su auge con los positivistas y su decadencia con las teorías contemporáneas y posmodernas, derivadas a su vez de la relatividad einsteniana y del principio de incertidumbre, por ejemplo.

Por ello, en el Diario de Colón y en las primeras manifestaciones de los cronistas se expresa la llamada palabra referida, con lo que las puertas del absurdo se abrían a multiplicidad de interpretaciones y a la inevitable resemantización de conceptos y hechos que en Latinoamérica tienen una lectura y una funcionalidad distintas. Amazonas, aniuros, acéfalos, etcétera, desfilaban en un ingenuo juego de desplazamientos por el territorio 
latinoamericano y se superponían o eliminaban a los auténticos representantes de nuestra fauna imaginada:

Colón descubre un mundo totalmente nuevo. Sin embargo, no acepta la realidad de este mundo como se le presenta, sino que, como es lógico, la acomoda a unos conocimientos y creencias previas, que le dan sus criterios de interpretación. Esta visión subjetiva y casi fantástica de la realidad se refleja de manera muy clara en algo tan elemental como las palabras con que describe lo que ve o lo que cree ver. (Orrego, 1991, p. 6)

De ahí que, volviendo a Asenov (1986), hablemos de un nivel denotativo y de uno connotativo en lo maravilloso real. Ambos aspectos son opuestos y, aunque proceden de una matriz básica como es lo maravilloso, sus intereses constitutivos son radicalmente distintos. Siguiendo al mencionado autor, este maravilloso real es instantáneo, impactante, efectúa una poderosa ruptura con lo que concebimos como realidad y motiva en el receptor -marcado por su percepción lógico/racional-el deslumbramiento, el asombro:

Lo maravilloso real, contrapartida de lo maravilloso falso, se manifiesta - como decíamos- en dos niveles intrínsecamente entrelazados. En el plano de la denotación, lo real maravilloso es explícito, "a flor de piel", recoge lo maravilloso "en estado bruto", lo representa de modo que infrinja las normas y suscite el efecto inmediato de sorpresa en personajes y lectores. Estos párrafos, marcados por Carpentier con una clave formal que vienen a ser aquellas partes del discurso con la intención de sorprender, asombrar, maravillar, admirar, contienen lo maravilloso significado por lo insólito, lo extraordinario, tanto bello como horroroso. Lo real maravilloso denotado abarca todos los contextos de la vida, sin desdeñar ninguno, que enmarcamos en los tres grandes grupos señalados. La teoría de los contextos de Carpentier se convierte en una práctica y lo real maravilloso de este nivel significa una indagación minuciosa que lo diferencia sustancialmente de otros procedimientos literarios. Descomponiendo la realidad, lo real maravilloso denotado crea imágenes precisas, aporta conocimientos, desentraña sustratos ocultos, emite juicios directos. En el campo de la denotación operan de una manera inmediata en los tres mecanismos señalados. (Asenov, 1986, p. 21)

Esta dinámica denotativa se manifiesta esencialmente en algunos factores como estos:

1. La "raza". La convivencia y fusión de las diferentes variedades raciales de América Latina otorga al continente una posibilidad mayor de relatos e historias imaginarias.

2. Lo social. Las diferencias ideológicas y socioeconómicas de cada grupo social explican las motivaciones de los individuos y las actitudes colectivas.

3. La cultura. Las expresiones artísticas e intelectuales de nuestros pueblos al entrar en contacto, a veces conflictivamente, conforman un corpus estético de gran belleza, complejidad y originalidad. 
Lo real maravilloso es producto de la mezcla de todo esto.

Además de estos factores, en el discurso de los escritores representativos de lo real maravilloso como Carpentier, Rulfo o García Márquez, se pueden distinguir dos estilos: uno culto, que incluye a los metalenguajes, y otro coloquial. El primero es hegemónico y por su intermedio se cumplen los postulados esenciales del método. El segundo es también funcional, porque es un vehículo de desmitificación, corta series temáticas, efectúa desplazamientos en el espacio y en el tiempo. La alternancia de ambos discursos puede producir el choque, el enfrentamiento. Asenov (1986) sostiene a manera de conclusión:

Partiendo de la premisa de que la obra literaria designa siempre una realidad extraliteraria, hay que investigar los lazos de la obra con el referente. Sobre la base de la tradición literaria y del plano de la expresión y la estructura de la obra, el receptor la juzgará de ficción, documental, fantástica, etc., sin embargo, lo documental, lo testimonial, el realismo en el sentido de estrechos lazos con el referente se detecta tanto a través de la denotación como de la connotación. (p. 22)

Así encontramos valores documentales que están al servicio de una visión realista, de una representación veraz del contexto extraliterario, en ningún momento debilitados por los medios. De acuerdo con lo planteado, a los lectores les corresponde también otorgar los espacios privilegiados y las simbologías que emanen de las obras pertenecientes a lo real maravilloso, pero estas son producto innegable de la propia dinámica sociocultural que expresa esa propuesta tan original.

Los autores consignados en este texto, como todos los escritores, establecen diferentes niveles de relación con su obra. Algunos como Carpentier, por ejemplo, no solo producen libros catalogados dentro de lo real maravilloso, sino que, además, se convierten en teóricos de esta propuesta, como lo demostró en el prólogo de El reino de este mundo (1949). Es decir, existía una clara intencionalidad de su parte por exponer en su obra sus hipótesis estético-culturales. De alguna manera, los otros autores incluidos en este grupo no desarrollaron de forma sistemática hipótesis acerca de lo real maravilloso, pero en distintas entrevistas, foros o discursos hicieron evidente una toma de posición con respecto a su movimiento. El mercado editorial y los vehículos de difusión masiva contribuyeron a la exposición pública y académica de estos narradores y, por lo tanto, los forzaron a exponer su arte poética y a desarrollar ciertos criterios formales.

En el caso de Rulfo y García Márquez, ellos tal vez no eran del todo conscientes de la resonancia que iban a conseguir Pedro Páramo (1955) y Cien años de soledad (1967), respectivamente. También es imperativo reparar en uno de los temas más conflictivos que afrontan estos narradores: el de la relación entre autor y crítico. Para algunos creadores, el vínculo fue auspicioso y novelas como El reino de este mundo, considerada fundadora del género, Pedro Páramo y Cien años de soledad se han convertido en 
reconocidos hitos de la nueva narrativa latinoamericana. Prácticamente lo mismo se puede decir de la relación entre el autor y el receptor, lo que para los escritores mencionados fue igualmente gratificante.

En lo real maravilloso, la creencia colectiva adquiere una practicidad evidente, puesto que ella es en América Latina la que da lugar a esta manera de comprender nuestra identidad. Es muy difícil que el postulado de la creencia colectiva se desenvuelva de mejor manera que en el espacio mítico de esta tendencia, ya que el primer requisito es, para Carpentier, la noción de fe, esa fe popular que propicia lo real maravilloso.

Para empezar, la sensación de lo maravilloso presupone una fe y más adelante el mismo Carpentier ubicará en un espacio geográfico de Latinoamérica aquello que le imprimió su principal experiencia, motivo central de su novela El reino de este mundo. (Bravo, 1978, p. 27)

\section{CONTEXTO Y SINCRETISMO}

El mundo era tan reciente que muchas cosas carecían de nombre y para mencionarlas había que señalarlas con el dedo.

(García Márquez, 1986)

Aún en la actualidad, en este gran espacio llamado América Latina, fusión de Comalas y Macondos, hay cosas que todavía carecen de nombre y a las que debemos señalar con el dedo. Pero más allá de lo lírico, aún resta un amplio corpus por investigar y redefinir.

Lo real maravilloso, desde la sistematización de Carpentier en El reino de este mundo, sintetiza un anhelo que pasa también por lo académico: el descubrimiento de nuestra identidad. Este deseo, como todo lo concebido en América Latina, se remonta al primer narrador oral que contó algún mito o leyenda cosmogónica en cuclillas, señalando con el índice a los astros, en Yucatán o los Andes. Este intento por explicar el origen del espacio donde nos ha tocado vivir es una de nuestras grandes herencias; esta curiosidad por problematizar nuestro origen condujo de manera inexorable a la elaboración de un modelo autónomo y propio. Tomando esta necesidad de explicarnos a nosotros mismos como punto de partida de cualquier aproximación a lo real maravilloso, llegamos a la conclusión de que el deslinde con el surrealismo europeo era imprescindible, de ahí que Carpentier, repuesto de su deslumbramiento por esta variedad del avant-garde europeo, firmara en 1930, al lado de once surrealistas disidentes, un manifiesto antibretoniano, $y$, aunque parezca contradictorio, aun en esto existe un agradecimiento implícito. Por ello, Müller-Bergh (1972) sostiene que "las inquietudes de los jóvenes surrealistas le inspiran la rebeldía contra la cultura occidental y refuerzan su conciencia del futuro de 
Hispanoamérica. Lo incuestionable es que el ejemplo surrealista confirma las ideas de Carpentier [...]" (p. 28).

Si hacemos un enfoque de nuestro continente, lo primero que percibiremos será la diversidad y los contrastes. A desiertos gigantescos e inclementes, le pueden seguir los lagos, ríos y océanos más altos y más extensos del mundo. Junglas tupidas y vírgenes se ven frenadas por cordilleras enormes. Al llano, que desafía en bajeza al nivel del mar, puede, en un breve recorrido geográfico, continuarle una desmesurada ciudad a cuatro o cinco mil metros de altura. En síntesis, nuestra topografía es un capricho desaforado para el que no se tomó en cuenta la regularidad y la simetría, tan caras a los grecorromanos, por ejemplo.

Otro catalizador de lo maravilloso en Latinoamérica, según Carpentier, es la coexistencia de diferentes tiempos y espacios. Más aún, lo real maravilloso se explica en términos de la dislocación del tiempo y el espacio. Carpentier sostiene que lo maravilloso se presenta cuando en una situación que parece normal, que se desarrolla de modo ordinario dentro de las dimensiones de tiempo y espacio, algo irrumpe súbitamente logrando que las cosas tomen la característica de "maravilloso". Sin embargo, este algo que sucede no es evidente; por el contrario, lo maravilloso en Carpentier parece provenir de una disrupción sutil. Según él, lo fantástico es inherente a las realidades naturales y humanas de tiempo y espacio; en este caso, la yuxtaposición improbable y las combinaciones maravillosas existen en virtud de la variada historia, demografía y política de Latinoamérica. (Bernal, 2006, p. 38)

Una segunda gran paradoja es aquella que está relacionada con los distintos estadios de evolución que vive el hombre latinoamericano: el eje de simultaneidades. Así observamos asombrados el despliegue tecnológico que está en nuestras manos en Buenos Aires, Brasilia, Bogotá o Lima, capitales signadas como cualquier otra por la automatización y la informática, por la comunicación audiovisual y la realidad virtual, y volvemos el rostro hacia una aldea ignota y anónima en la que se danza antes de la muerte, inspirados por el espíritu protector de una deidad y en la que una simple computadora sería poco menos que un milagro que alteraría la cosmología que sus pobladores arrastran desde centurias.

Un tercer elemento que sufre un proceso de tesis y antítesis, extrañamente dialéctico, es el de las creencias: las mutaciones por las que pasa la fe en Latinoamérica es, qué duda cabe, uno de los más fascinantes espectáculos que podemos admirar y hasta experimentar en carne propia. Nos convertimos en partícipes de las muestras más tradicionales y hasta góticas de las religiones occidentales, encabezadas por la judeocristiana, los rezagos de sectas orientalistas y cultos oceánicos, para llegar luego a la amplia gama de manifestaciones sobrenaturales y folclóricas en las que la magia, el vudú, el chamanismo y la macumba no están ausentes. 
En una travesía imaginaria, podríamos ser testigos de un exorcismo católico y de uno indígena. Percibiríamos los rasgos marcadamente andinos de un Cristo de Nazaret curiosamente crucificado en el Perú o en Bolivia, o el de una extraña Virgen negra en Cuba al lado de la que reposan unos caracoles, los que al ser arrojados podrían servir para atisbar el futuro. Quedaríamos impregnados para siempre de la imagen de un visionario selvático que ingiere un alucinógeno y llama a Dios o al diablo, ya que ambos poseen poderes, y se convertiría en siervo del primero que acudiera en su ayuda. "Más aún, para Carpentier, la historia de Latinoamérica no es más que la narración de lo inusual. Dice que mientras en Europa escuchó leyendas de lo fantástico, en Latinoamérica lo fantástico formaba parte de la realidad y la historia" (Bernal, 2006, p. 40). Así, es notorio que los rasgos sincréticos y mestizos de nuestra América revelan no solo nuestra situación, sino que de forma inevitable generan un espacio de sucesos y hechos que merecen una nueva lectura, puesto que van a forjar paulatinamente el capital simbólico, conformado por la educación, el arte y la historia cultural de este subcontinente.

Es, pues, de este contexto del que emergerá el esteta literario, el creador, que interprete y exprese a su manera esa realidad en la cual se basa y de la cual es producto. Las primeras tensiones se producirán entre dos campos claramente diferenciados: el literario, que es el resultado de fuerzas específicas desarrolladas dentro de un espacio social determinado -en este caso, la situación latinoamericana (esencialmente la peruana)-, y el estrictamente coyuntural espacio sociohistórico. Lo real maravilloso permite también dejar atrás los prejuicios reduccionistas que colocaban al arte en la situación de ser un campo cerrado en sí mismo, cercano al viejo tópico hedonista de "el arte por el arte" o en un triste papel de subordinación con respecto al entorno político o económico imperante.

El capital simbólico acumulado es utilizado por cada artista de distinta forma. En nuestro caso, los narradores representativos de lo real maravilloso ejercen su autonomía e individualidad de una manera crítica y cuestionadora, buscando, además, mostrar una suerte de "espíritu" cultural, racial, artístico e histórico que signifique volver la vista hacia nosotros mismos. Una manera de lograrlo es la de reconocer nuestras particularidades.

Lo real maravilloso se centra en la relación entre hombre, naturaleza e historia, y en la forma en que tales elementos interactúan para crear una cultura única. Dada la historia de conquista y colonia en Latinoamérica, lo real maravilloso americano es un término que brotó de la sensación de desarraigo y tuvo como consecuencia una imagen de Latinoamérica como tierra utópica. De acuerdo con González Echevarría, el trabajo de Carpentier se sitúa en esta tradición posromántica. (Bernal, 2006, p. 42)

Todos los laberínticos conceptos antes mencionados, para los que las palabras frontera o límite no significan nada y cuyo vigor es tan grande que arrasan con cualquier 
intento de decodificación o desmonte de las piezas absurdas que lo conforman, constituyen en esencia lo real maravilloso. Son más que discutibles intentos de englobar algo que rebasa el terreno de las definiciones y que está extraordinariamente vinculado a los actos espontáneos del hombre y la naturaleza latinoamericanos.

Desde luego, proponer que la realidad es maravillosa, como hizo Carpentier, no es más comprometido que suponerla extraña, como Todorov parece deducir de la cosmovisión contemporánea. Si suponemos que el realismo mágico constituyó una reproducción fiel de la maravillosa realidad americana, podemos excluir esa literatura del ámbito de la literatura fantástica. Pero eso no resuelve el problema: lo indudable, lo decisivo, es que lo maravilloso continúa percibiéndose en contraste con "lo normal", y quizá también en contraste con "lo anormal", en los propios textos o en relación con el contexto literario europeo e incluso con el latinoamericano. Y ahora cada cual puede sacar sus propias conclusiones: si se piensa que lo sobrenatural actúa en Cien años de soledad según sus propias leyes y no es en absoluto inquietante, el realismo mágico puede quedar encuadrado en el ámbito de lo maravilloso, próximo a los cuentos de hadas y a lo milagroso cristiano. Yo prefiero otra interpretación: el realismo mágico ha de relacionarse con los límites del racionalismo o del irracionalismo tal como se han profesado en la cultura occidental, con el cuestionamiento de esa manera de ver el mundo, con la fascinación y el temor que ejerce lo desconocido, lo que amenaza con desestabilizar un equilibrio siempre precario. Cuando Carpentier pretendió dar testimonio de una realidad distinta - tan ajena al racionalismo europeo como al irracionalismo también europeo de los surrealistas-, entendió que esa realidad tenía que ver con una dimensión oculta y permanente del hombre. (Fernández, 2001, p. 297)

El simple hecho de oponer conceptos y de no hallar una correspondencia absoluta entre ellos nos lleva a conclusiones dispares. Por ejemplo, si consideramos al realismo mágico como una posible reproducción de la realidad maravillosa latinoamericana, encontraríamos que el mérito de los narradores que han desplegado su esfuerzo en ese enfoque residiría en su objetividad - si cabe el término- para reconstruir con palabras toda una visión del mundo. Si, por otro lado, el realismo mágico debe medirse y contrastarse con el racionalismo e irracionalismo europeos, como pretendió Carpentier, pues tenemos un viraje trascendente respecto a los paradigmas acerca de la realidad. El asunto, entonces, derivará de un simple afán referencialista, que se contenta solamente con la descripción maravillada de la realidad latinoamericana, hacia la demostración, a través de la literatura, de un conjunto de elementos que permiten leer nuestro contexto de manera óptima, utilizando para ello el mediador más adecuado: lo real maravilloso.

De acuerdo con lo mencionado, debemos remontarnos a la perspectiva que puede tener un observador foráneo que ingresa a este conglomerado de paisajes, etnias y culturas, y que podría estar representado por los viajeros europeos que arribaron a nuestras costas desde la época del descubrimiento y de la conquista. Así podemos 
notar que un antecedente lejano en el tiempo, mas no tanto en la concepción del mundo americano de Carpentier, Asturias, Rulfo o García Márquez, son los testimonios y crónicas de los forasteros peninsulares que contemplaron, entre fascinados e incrédulos, el despliegue de fantasía ofrecido ante su vista, manifestado de la manera más espontánea y al que misteriosamente le atribuyeron significados que no poseían o también a los que enriquecieron con su propia exageración, motivados tal vez por esa atmósfera sobredimensionada que los envolvió y sedujo. Ese es el caso, por ejemplo, del nombre del río Amazonas, que surgió cuando los expedicionarios hispanos juraban haber enfrentado a temibles y gigantescas mujeres (otra vez la desmesura) que se desempeñaban en la lid como los más avezados soldados y que por sus características no podían ser otras que las legendarias guerreras de la mitología clásica lideradas por Pentesilea o Hipólita.

Igualmente, es remarcable la búsqueda constante que acometieron los españoles en el Cusco y otras ciudades para desenterrar supuestos tesoros incaicos a los que atribuían dimensiones portentosas, o las sorprendentes expediciones para hallar El Dorado. Si a ello sumamos los testimonios del cronista Bernal Díaz del Castillo, quien afirmó que existían en el Río de la Plata cruces de pez y cerdo, y más aún hombres peces que servían de alimento a los pobladores, entenderemos por qué José Martí se pronunció tiempo más tarde de manera tan contradictoria cuando exclamó: "No habría poema más triste y hermoso que el que se pueda sacar de la historia americana" y " $i Q u e ́$ novela tan linda la historia de América!". Definiciones que prácticamente sirven de prólogo a lo dicho por su compatriota Alejo Carpentier en El reino de este mundo: “¿Pero qué es la historia de América toda sino una crónica de lo real maravilloso?".

Carpentier explicó la presencia de lo maravilloso en la cultura latinoamericana como sincrética, no solo a causa de la convivencia de personas de diferentes razas, sino también por la asimilación cultural de influencias externas a Latinoamérica, como, por ejemplo, la Revolución francesa y la colonización cultural de Europa y Norteamérica. Conocer y entender estas influencias no significó para Carpentier que Latinoamérica hubiera sido colonizada. Por el contrario, todos estos eventos le dieron a Latinoamérica una visión del mundo más amplia que la que podrían tener los europeos. (Bernal, 2006, p. 42)

Es evidente que en este terreno de conflictos y tensiones ya tenemos dos elementos claramente diferenciados: realidad e imaginario popular. ¿Dónde comienza uno y termina el otro? Lo primero es determinar que prácticamente existen dos posibilidades de asumir esta realidad: retratándola fielmente a la manera de los narradores europeos de la escuela realista, leales a un credo donde los hechos objetivos y los factores interactuantes del entorno son fundamentales; o reelaborándola artísticamente, echando mano a ese personal capital simbólico que todos poseemos y al talento y originalidad que distingue a un creador de un mero intérprete intelectual. 
Definitivamente nos quedamos con la segunda opción, la cual se divide a su vez en otros posibles sistemas de análisis e interpretación. Uno de ellos es evaluar las características intrínsecas de las obras literarias, es decir, el famoso "criterio de literariedad" o quizá los intentos inmanentistas expresados por los formalismos (ya sea ruso con el Círculo de Moscú o la Opoiaz, o el corpus estructuralista francés con Genette, Barthes y compañía). Otro es el desfasado método biográfico, que, a pesar de la renovación efectuada por Sartre cuando escribió un ensayo sobre Flaubert y su obra, resulta insuficiente y de muchas maneras se ubica dentro de los paradigmas del positivismo. Finalmente, podemos tomar en cuenta en esta hipótesis particular a la intertextualidad.

Esta última opción puede ser la más apropiada, ya que gran parte de la mitología latinoamericana se nutre de dos visiones: la propia cosmovisión nativa, a la que Asenov (1986) denomina maravilloso real, y la perspectiva de los conquistadores, a la que el mismo autor llama maravilloso falso. De la fusión de ambas surge esa neomitología expresada en términos literarios por García Márquez, Rulfo o Carpentier.

Los rasgos intertextuales los hallamos en la rica tradición escrita y oral de las grandes civilizaciones precolombinas, pero también en las crónicas y testimonios de los colonizadores europeos que inducen a los autores representativos de lo real maravilloso a la creación de personajes que están profundamente vinculados a los bestiarios medievales europeos y a las figuras judeocristianas y orientales. Estos, a su vez, proceden de un complejo y ancestral proceso de encuentros y desencuentros donde el aporte clásico grecorromano es decisivo, sobre todo tomando en cuenta que los conquistadores hispánicos del siglo Xvı todavía se ubicaban a caballo entre las represiones escolásticas medievales y el desborde libertario del Renacimiento.

América Latina, el Nuevo Mundo, era un espacio vacío para los europeos y, por ello, no hallaron mejor actitud que "llenarlo", poblándolo de sus mitos y creencias. De ahí pues, de un intrincado proceso de inclusiones y exclusiones, aparecen en las obras literarias europeas y de su yuxtaposición o, mejor, de su mezcla con los ritos nativos latinoamericanos surge esta dualidad de realidad e imaginario popular. No debemos olvidar que el Ti Noel de El reino de este mundo de Carpentier o el José Arcadio Buendía de Cien años de soledad de García Márquez le deben mucho a Gargantúa y Pantagruel de François Rabelais. 


\section{LA MUERTE EN AMÉRICA LATINA}

Estoy aquí, boca arriba, pensando en aquel tiempo para olvidar mi soledad. Porque no estoy acostada solo por un rato y ni en la cama de mi madre, sino dentro de un cajón negro como el que se usa para enterrar a los muertos. Porque estoy muerta.

(Rulfo, 1984, p. 63)

Esta concepción y reconocimiento de la muerte que nos ofrece Juan Rulfo en Pedro Páramo es, sin duda, una de las constantes más marcadas y fascinantes de lo real maravilloso, y abre la puerta principal de aquel mundo donde las reglas solo existen para ser violadas: el mundo de lo mágico.

El concepto de la muerte dentro de los paradigmas de la cultura occidental implica de una manera radical y totalizadora no un fin, sino el fin, y la prueba de ello son los innumerables ejemplos que ha exhibido su notable tradición literaria. Es decir que la frontera definitiva y última, el espacio finito, el muro de todo lo vital, es la muerte. Siglos después, en el territorio que divide al neoclasicismo, el Sturm und Drang y el romanticismo, Goethe en su Fausto nos coloca frente al protagonista de esa obra y su temor de morir o en todo caso de deteriorarse: “ $\mathrm{S}$ Si yo pudiera decirle al instante: / ¡Perdura! ¡Eres tan hermoso! / Entonces podrías cumplir con tu función: / Podría pararse el reloj, caer las agujas / y el tiempo abolirse en mí" (Goethe, 1981, p. 31). Además, Fausto se presenta hastiado y arrepentido, y hasta parece simbólicamente que pide una nueva oportunidad, un intento de salvación de su alma, ya que luego no podrá hacer nada, y será incapaz de cualquier conato de reconsideración porque sencillamente no existe ese luego después de la muerte.

En el ámbito occidental, cuando se alude al alma, espíritu o a sus manifestaciones fantasmales, estas habitan una dimensión paralela o compartimiento estanco que solo en ocasiones pierde la línea divisoria y es capaz de coexistir e invadir el terreno de lo real, lo humano y en última instancia de los vivos. Por el contrario, en Latinoamérica la vida y la muerte no solo conviven, sino que son expresiones levemente diferenciadas de lo mismo y actúan como una sola en un devenir que solo atribuye a la segunda algo más de amplitud de desplazamientos y de comunicación.

De esta forma, los ritos mortuorios de las civilizaciones precolombinas denotaban una mayor compenetración entre los deudos y el fallecido que los vínculos desarrollados por la cultura occidental y sus muertos más allá de estatuas o monumentos; así queda demostrado con las ofrendas que acompañan al finado en su largo viaje y la tendencia al embalsamamiento, que implicaba un respeto a la imagen que el difunto tuvo en vida y al deseo de que esa apariencia física permanezca inalterada o, por lo menos, se retarde el proceso de deterioro que pudiera sufrir. 
Lo expuesto se hace patente en la forma en la que apelamos a los muertos para solicitar su intervención ante una dificultad o para invocar su poder y conseguir algún anhelo personal. En síntesis, nos dirigimos a ellos - generalmente seres queridos o familiares-como a divinidades menores, una suerte de dioses domésticos, que por sus propias posibilidades o por su capacidad de intermediarios ante el Dios mayor poseen la virtud de solucionar nuestros problemas o al menos de intentarlo. En el otro extremo, los difuntos - generalmente ajenos, desconocidos - tienen la energía y la voluntad suficientes para atemorizarnos, ya sea profiriendo sonidos o movilizando objetos en un intento de intimidación psicológica. Esto lo percibimos en esa actitud subconsciente por la cual atribuimos a cualquier desplazamiento de lo inanimado o a alguna voz o grito el carácter de lo fenecido, una emanación de ultratumba, etcétera.

Dentro del vasto mundo narrativo de García Márquez, la muerte es enfocada de manera similar. Una de las tantas veces en que lo mencionado se percibe es en un encuentro entre José Arcadio Buendía, que asesinó a Prudencio Aguilar, y su víctima:

Una noche en que no podía dormir, Úrsula salió a tomar agua en el patio y vio a Prudencio Aguilar junto a la tinaja. Estaba lívido, tratando de cegar con un tapón de esparto el hueco de su garganta. No le produjo miedo, sino lástima. Volvió al cuarto a contarle a su esposo lo que había visto, pero él no le hizo caso. "Los muertos no salen", dijo. "Lo que pasa es que no podemos con el peso de la conciencia". Dos noches después, Úrsula volvió a ver a Prudencio Aguilar en el baño, lavándose con el tapón de esparto la sangre cristalizada del cuello. Otra noche lo vio paseándose bajo la lluvia. José Arcadio Buendía, fastidiado por las alucinaciones de su mujer, salió al patio armado con la lanza. Allí estaba el muerto con su expresión triste. “Vete al carajo”, le gritó José Arcadio Buendía. “Cuantas veces regreses volveré a matarte". Prudencio Aguilar no se fue ni José Arcadio Buendía se atrevió a arrojar la lanza. Desde entonces no pudo dormir bien. Lo atormentaba la inmensa desolación con que el muerto lo había mirado desde la lluvia, la honda nostalgia con que añoraba a los vivos, la ansiedad con que registraba la casa buscando el agua para mojar su tapón de esparto. "Debe de estar sufriendo mucho", le decía a Úrsula. "Se ve que está muy solo". Ella estaba tan conmovida que la próxima vez que vio al muerto destapando las ollas de la hornilla comprendió lo que buscaba; desde entonces le puso tazones de agua por toda la casa.

Una noche en que lo encontró lavándose las heridas en su propio cuarto, José Arcadio Buendía no pudo resistir más. “Está bien, Prudencio", le dijo. "Nos iremos de este pueblo, lo más lejos que podamos y no regresaremos jamás. Ahora vete tranquilo". (García Márquez, 1986, p. 25)

Este episodio marcó el éxodo de los Buendía y sus seguidores hasta esa tierra mítica cuyo nombre se revela en un sueño: Macondo. Notemos que la primera actitud de Úrsula - José Arcadio es de alguna manera natural, porque el aspecto racional (clásico occidental) reacciona frente al aparecido como ante una "alucinación" y José Arcadio trata de 
convencer a su esposa de que esa sugestión es causada por el cargo de conciencia. Sin embargo, ante la reiterada presencia del espectro, Úrsula asume una actitud compasiva y su marido, doblegado por las evidencias, acepta la corporización de Prudencio Aguilar (lo real maravilloso), primero agrediéndolo y luego disculpándose con él y viéndose forzado a marcharse de su terruño, derrotado.

Es necesario aclarar que García Márquez incluye en su concepción de lo real maravilloso un sugestivo humor negro:

[...] Amaranta no se sintió frustrada, sino, por el contrario, liberada de toda amargura, porque la muerte le deparó el privilegio de anunciarse con varios años de anticipación. La vio un mediodía ardiente, cosiendo con ella en el corredor, poco después de que Meme se fue al colegio. La reconoció en el acto, y no había nada pavoroso en la muerte, porque era una mujer vestida de azul con el cabello largo, de aspecto un poco anticuado, y con un cierto parecido a Pilar Ternera en la época en que las ayudaba en los oficios de cocina. Varias veces Fernanda estuvo presente y no la vio, a pesar de que era tan real, tan humana, que en alguna ocasión le pidió a Amaranta el favor de que le ensartara la aguja [...].

La noticia de que Amaranta Buendía zarpaba al crepúsculo llevando el correo de la muerte se divulgó en Macondo antes del mediodía, y a las tres de la tarde había en la sala un cajón lleno de cartas. Quienes no quisieron escribir le dieron a Amaranta recados verbales que ella anotó en una libreta con el nombre y la fecha de la muerte del destinatario. "No se preocupe", tranquilizaba a los remitentes. "Lo primero que haré al llegar será preguntar por él y le daré su recado". (García Márquez, 1986, pp. 220-221)

La actitud ante esa situación extrema es descabellada y se presenta como un proceso tan natural como cómico. La insólita asimilación de un evento como este le otorga mayor verosimilitud a la muerte y la transforma en la piedra de toque de toda la obra y, en consecuencia, del código que gobierna lo real maravilloso. No podemos hallar un espacio ideológico más evidente para incluir la noción de la creencia que la muerte. Por supuesto, uno de los primeros requisitos que esboza Alejo Carpentier en el prólogo de $E l$ reino de este mundo es la fe, y esa fe debe estar depositada en lo maravilloso. De acuerdo con ello, la creencia colectiva que permite la existencia de una obra de arte ubicada dentro del universo temático de lo real maravilloso define, finalmente, dicho código y motiva una reflexión plural que siente y piensa lo mismo.

Por lo tanto, uno de los grandes espacios temáticos de lo real maravilloso, como es la muerte, despierta en el lector latinoamericano una serie de imágenes que pertenecen a todos y, además, contribuyen a la aceptación de cualquier obra que consigne dicho tópico, con lo que algunos conceptos en torno a la creencia estarían demostrados $y$, al mismo tiempo, relacionados con el horizonte de expectativas de los receptores regionales. 


\section{REFERENCIAS}

Arguedas, J. M. (2004). El zorro de arriba y el zorro de abajo. En C. M. Pinilla (Ed.), ¡Kachkaniraqmi! ¡Sigo siendo! José María Arguedas, textos esenciales. Lima: Fondo Editorial del Congreso del Perú.

Asenov, V. (1986). Lo real maravilloso, un método definidor en las letras latinoamericanas. Imán, 2, 24-38.

Bernal, M. (2006). Más allá de lo real maravilloso: el surrealismo y el Caribe. Bogotá: Ediciones Uniandes.

Bravo, J. A. (1978). Lo real maravilloso en la narrativa latinoamericana. Lima: Editoriales Unidas.

Carpentier, A. (1994). El reino de este mundo. Puerto Rico: Universidad de Puerto Rico. (Trabajo original publicado en 1949).

Fernández, T. (2001). Lo real maravilloso de América y la literatura fantástica. En D. Roas (Comp.), Teorías de lo fantástico (pp. 283-297). Madrid: Arco/Libros.

García Márquez, G. (1986). Cien años de soledad. Bogotá: Oveja Negra.

Goethe, J. (1981). Fausto. Lima: Universo.

Müller-Bergh, K. (1972). Asedios a Carpentier. Once ensayos críticos sobre el novelista cubano. Santiago de Chile: Editorial Universitaria.

Orrego, J. (1991). Sirenas y ruiseñores. El Peruano, p. 12.

Roas, D. (2001). La amenaza de lo fantástico. En Teorías de lo fantástico (pp. 7-44). Madrid: Arco/Libros.

Rodríguez, J. (2004). Dos formas de asumir lo maravilloso americano: Alejo Carpentier y José María Arguedas. Revista Hojas Universitarias, 57, 66-71.

Rulfo, J. (1984). Pedro Páramo. Bogotá: Oveja Negra. 